\title{
Smart Concrete Curing System
}

\author{
Dr.V. Mallikarjuna Reddy ${ }^{1 *}$ and $S$. Hamsalekha ${ }^{2}$ \\ ${ }^{1}$ Professor \&Head, Department of Civil Engineering, GokarajuRangaraju College of Engineering and Technology, \\ Hyderabad, Telangana, 500090, India. \\ ${ }^{2}$ Post graduate student, Department of Civil Engineering, GokarajuRangaraju College of Engineering and Technology, \\ Hyderabad, Telangana, 500090, India.
}

\begin{abstract}
In the present era, water scarcity is the biggest problem. In Construction potable water is required for mixing and curing of concrete. The curing process is required for 28 days. So the water requirement in the construction field for curing purposes is very large. Due to various reasons, potable water availability is decreasing day by day. So it is required to spend a considerable amount on the procurement of water. To control the wastage of water for curing it is necessary to use water in a controlled manner by adopting advanced technology. It is known as a smart concrete curing system. The smart concrete curing system is developed to create an automatic curing mechanism to supply water for curing depending on the availability of moisture in the concrete and surrounding temperature using moisture sensor. The system will be connected to the internet using Wi-Fi. The current moisture content level of the concrete structure and the pump status will be pushed to the cloud. A mobile app will access this data from the cloud. So that the curing process monitoring can be done remotely. Results shown that strength of the cube with smart concrete curing system is more than the strength of the cube with immersion curing.
\end{abstract}

\section{Introduction}

Curing is important for concrete structures to achieve the required strength. Curing is a method to harden the concrete under surrounding humidity and temperature which are responsible for the setting of cement components. Curing is a process for maintaining the required moisture and temperature throughout the strengthening period. As lots of water is wasted for the curing process, to reduce the wastage of water automatic curing process is implemented. Undesired water content causes internal heating and results in cracks. Also, there is no control over the amount of water used thus water wastage is also a concern. But unskilled labours and undesired amount of water usually stands as a problem in curing. This may lead to unbalanced moisture and temperature levels which affects the strength and durability of concrete. So an efficient mechanism for curing is needed. Since the development of different sensors automation has become very common. Automation has reduced human involvement and has made it easier for production and management. Automation in civil engineering is increasing along with the use of different sensor systems for monitoring and controlling different functions. The smart concrete curing system is developed to create an automatic curing mechanism to supply water for curing depending on the availability of moisture in the concrete and surrounding temperature. The moisture content of the structure is detected by using a moisture sensor without human intervention. Whenever moisture content decreases in the structure the sensors will automatically turn the pumping motor ON. When moisture content reaches the required level the motor will OFF automatically. This smart curing system project requires Sensors, $0.25 \mathrm{Hp}$ motor, Arduino microcontroller, PCB, etc. Arduino microcontroller is programmed to collect the input signal according to the moisture content of the concrete structure

\section{Necessity of Research}

The strength and durability of concrete are attained only by proper curing. It is very essential to maintain the proper moisture content in concrete throughout the hydration process. Curing helps in mitigating cracks that affect the durability and life of the concrete. Thus curing is an essential process in concrete structures. Due to the increase in water scarcity, it is important to conserve water and use it 
in a controlled manner for the curing of concrete structures.

\section{Literature review}

Shima Taheri (2019) reviewed sensors that are used in the construction field to monitor the health of concrete structures. Focused on monitoring parameters. Many examples with advantages and drawbacks are discussed.

Joaquín Cabezas et al (2018) worked on the design, construction, and testing of an embedded sensor system to monitor the curing process of concrete. Tested in laboratory and civil works. The system is implemented with low cost and reliability.

Nrutya N. Gandhi et al (2018) developed a smart irrigation system that provides water to plants automatically depending on their requirements. It can reduce water consumption by setting the threshold value to maintain optimum water content. By this technique, soil runoff is reduced.

Kanchan Ambekar and K.U. Gandhare (2017) experimented on different curing methods like spraying, immersion, and drip curing methods. The strength of the drip curing method was more compared to other methods and also the amount of water saved is more.

T.JamesKelvin Christy et al (2016) experimented at the lab-scale level on the Automatic Curing Process. It is water-conserving technology that consists of a sensor, microcontroller and water pump. The amount of water for this technique is reduced and money spent on curing also reduced.

Neerej K.P et al (2016) worked on the concept of an automatic curing system that allows monitoring the moisture and temperature inside the concrete block which are responsible to achieve a longer lifetime. This system also allows for real-time monitoring.

S. Darshna et al (2015) experimentally investigated automatic irrigation which helps in water conservation and providing required water to the plants. Sensors are installed in the field which is connected to the microcontroller to transmit the soil temperature and soil moisture data to estimate the demand for water

\section{Objectives}

The main objective of this research is to monitor the moisture level of concrete structure using a moisture sensor and to maintain the required water content throughout the curing process. Due to the growth of the population, water demand is exceeding the supply. If the demand for water continues, we would face a scarcity problem. So that there is a need to use water in a controlled manner. During concrete curing, the water requirement is not monitored. Even when the concrete is moist enough, water is still provided. This water is not absorbed by the concrete and thus is wasted. Hence a system to monitor the water requirements of the concrete structure is needed. The curing process is done effectively with a smart concrete curing system and reduces the wastage of water. By effective curing strength of concrete structure increases. As Smart concrete curing system is an automatic process so that men/women's power reduces and cost for curing also reduces.

\section{Experimental work}

\subsection{Process}

Experimental work is done in the laboratory using M20 grade concrete, cubes of size $150 \mathrm{mmX} 150 \mathrm{mmX} 150 \mathrm{~mm}$ were cast. The curing was done in two methods one is Immersion curing and another is Smart concrete curing.

For immersion curing, the cube is immersed in a water tub for 28 days. For smart concrete curing, the Sensor was inserted inside the concrete structure and the sensor is connected to the microcontroller with a ground pin, power pin, and analog pin. This microcontroller is connected to motor and power with the USB connector. The microcontroller is programmed to collect the input signal according to the moisture content of the concrete structure. The system will be connected to the internet using Wi-Fi. The current moisture content level of the concrete structure and the pump status will be pushed to the cloud. A mobile app will access this data from the cloud. So that the curing process monitoring can be done remotely.

Moisture value is taken after 24 hours of casting the structure because we start the curing process after 24 hours. Based on the observations we set the value of moisture sensor at 400 which is fixed as the threshold value. If the value increases the moisture in the structure decreases, then the pump automatically turned ON. If moisture value reaches 400 then automatically pump turned OFF. These values we can see on a mobile app from anywhere with Wi-Fi connection to the node MCU. 


\subsection{Moisture sensor}

It measures the moisture content of the concrete structure. It gives digital value for moisture content present in the structure.

\subsection{Node MCU}

It is an open-source IOT platform, which allows you to collect the information from the sensor and give output. It has a microcontroller, WIFI chip and Relay module by this curing process that can be automated and monitored remotely.

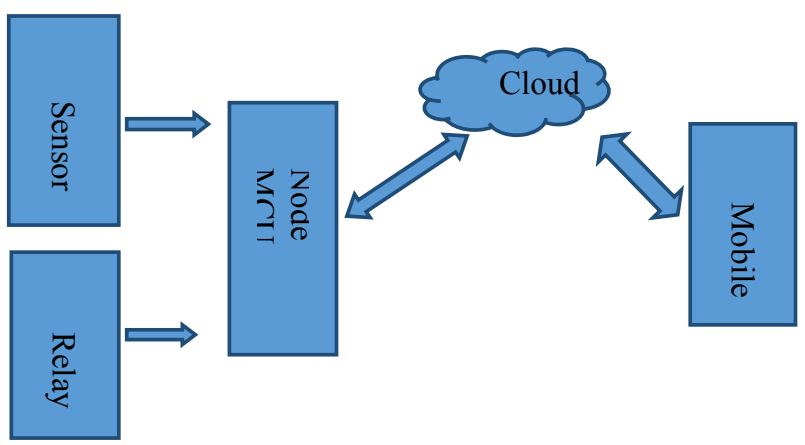

Fig. 1. Basic IOT concept

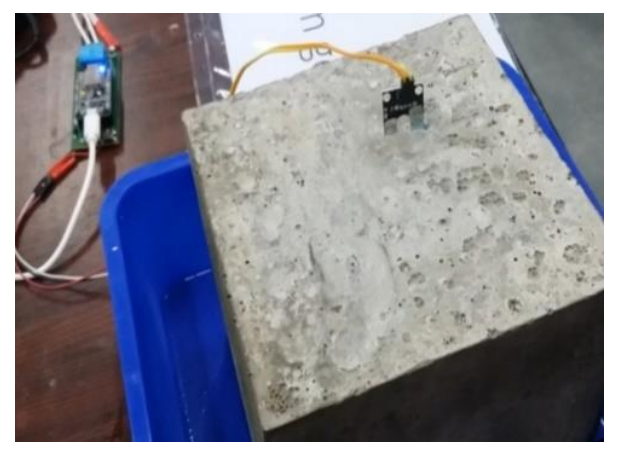

Fig. 2. Smart concrete curing

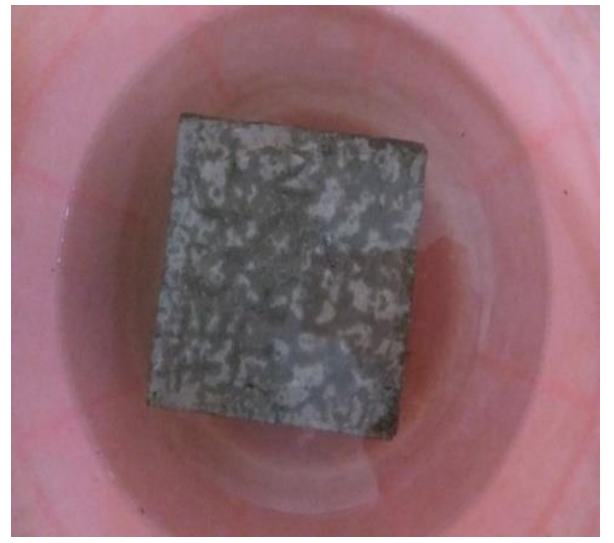

Fig. 3. Immersion curing

\section{Smart concrete curing system2}

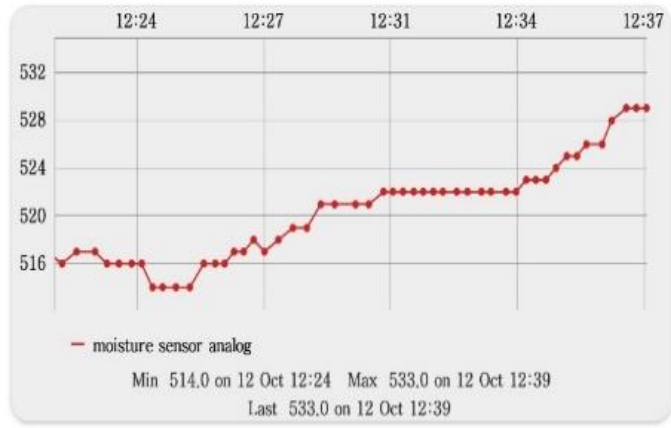

Fig. 4. Moisture content of the structure

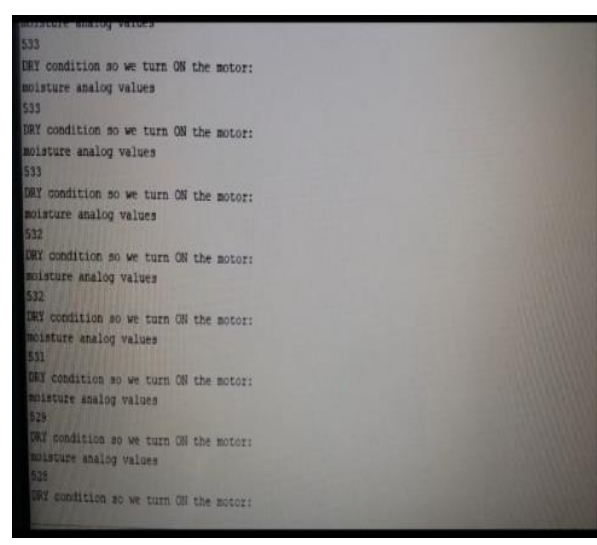

Fig. 5. Moisture content and motor status

\section{Results and discussion}

Curing done by Smart concrete curing system, the moisture values are recorded in the mobile app in the form of the graph as shown in Fig.4 and also a laptop is connected to the system which shows the values on the screen as shown in Fig.5. This process is continued for 28 days and then compressive strength of cube is tested.

Table 1

\begin{tabular}{|l|l|l|l|}
\hline $\begin{array}{l}\text { Type of } \\
\text { curing }\end{array}$ & $\begin{array}{l}\text { Compressive } \\
\text { force }\end{array}$ & $\begin{array}{l}\text { Area } \\
\text { of } \\
\text { cube }\end{array}$ & $\begin{array}{l}\text { Compressive } \\
\text { strength }\end{array}$ \\
\hline $\begin{array}{l}\text { Smart } \\
\text { curing }\end{array}$ & $574 \mathrm{kN}$ & 22500 & $25.5 \mathrm{~N} / \mathrm{mm}^{2}$ \\
\hline $\begin{array}{l}\text { Immersion } \\
\text { curing }\end{array}$ & $562 \mathrm{kN}$ & 22500 & $\begin{array}{l}24.97 \\
\mathrm{~N} / \mathrm{mm}^{2}\end{array}$ \\
\hline
\end{tabular}

The compressive strength of cube for 28 days should gain $99 \%$ of characteristic strength. The cube under Smart concrete curing has attained the strength of $25.5 \mathrm{~N} / \mathrm{mm}^{2}$ whereas the cube underimmersion curing 
has attained the strength of $24.97 \mathrm{~N} / \mathrm{mm}^{2}$. The strength developed for smart concrete curing system was greater than the immersion curing method.

\section{Conclusion}

Smart concrete curing system allowed to maintain the required moisture content throughout the curing process, by maintaining the required moisture level cube achieved compressive strength more compared to immersion curing. It is concluded that Smart concrete curing is an effective method for curing to get the required strength and durable structure. By using this system men power and wastage of water also reduced.

\section{Future scope}

This project can be extended by adding strength detecting sensors so that the curing process can be turned off after reaching the required strength. Also, a mobile application can be designed to get notification about the strength and curing process of the structure, so that time and cost of construction can be reduced.

\section{References}

1. Gupta, A.K., Singh, S.K., Reddy, S., Hariharan, G. Prediction of flow stress in dynamic strain aging regime of austenitic stainless steel 316 using artificial neural network. Materials and Design, 35, pp. 589-595. Cited 52 times (2012)

2. Jaoquin cameras, Trinidad Sanchez, Juan Antonio Gomez-galan, Hector Cifuentes and Ramon Gonzalez, "Compact embedded wireless sensor-based monitoring of concrete curing", Multidisciplinary digital publishing Institute, MDPI, (2018).

3. Kanchan Ambekar and Gandhare K.U "Developing a new curing technique-'Drip curing", International Journal for Research in applied science and Engineering technology, IJRASET, Volume 05, Issue 07, (2017).

4. Nayak, P., Devulapalli, A. A Fuzzy LogicBased Clustering Algorithm for WSN to Extend the Network Lifetime. IEEE Sensors Journal, 16 (1), art. no. 7222367, pp. 137-144. Cited 213 times. (2016).

5. Nayak, P., Vathasavai, B. Energy Efficient Clustering Algorithm for Multi-Hop Wireless Sensor Network Using Type-2 Fuzzy Logic. IEEE Sensors Journal, 17 (14), art. No. 7938335, pp. 4492-4499. Cited 68 times. (2017).
6. Neerej K.P and Abraham sudharsonponraj "Automatic curing system for concrete structures", National conference on science Engineering and technology, NCSET, Volume No 04, Issue 06, (2016).

7. Nrutya N. Gandhi, kinjal N. patel, prof. Abhishek patel, "Water saving irrigation automatic agricultural controller under Vishvakarma Yojana", Journal of IRJET, Vol. 05, issue:04, p-ISSN: 2395-0072, (2018).

8. S. Darshna, T. Sangavi, Sheenamohan, A. Soundharya, Sukanya Desikan, "Smart irrigation system", journal of electrical and communication engineering, IOSP, Vol.3, Issue 3 pp32-36, (2015).

9. Shima Taheri, "A review on five key sensors for monitoring of concrete structures", journal of ELSEVIER, vol.204, 492-509, (2019).

10. Singh, S.K., Mahesh, K., Gupta, A.K. Prediction of mechanical properties of extra deep drawn steel in blue brittle region using Artificial Neural Network. Materials and Design, 31 (5), pp. 2288-2295. Cited 55 times (2010).

11. Singh, S.K., Mahesh, K., Kumar, A., Swathi, M. Understanding formability of extra-deep drawing steel at elevated temperature using finite element simulation. Materials and Design, 31 (9), pp. 4478-4484. Cited 54 times (2010).

12. Naspuri Arun Raju, T. Suresh Kumar, International Journal of Innovative Technology and Exploring Engineering, Vol. 8 no. 11, pp: 3860-3864, (2019)

13. Mallikarjuna Reddy, V., Praveen, R.Effect of polyethylene glycol in self-curing of selfcompacting concrete. International Journal of Recent Technology and Engineering, 8(3), pp. 7280-7283, (2019)

14. Mallikarjuna Reddy, V., Vasanthi, S.Effect of elevated temperatures on fiber reinforced selfcompacting concrete. International Journal of Recent Technology and Engineering, 8(3), pp. 7775-7778, (2019)

15. Mallikarjuna Reddy, V., Bhaskar, B.Mechanical behaviour of self-compacting concrete by using M-sand \& rice husk ash, 8(10), pp. 3320-3323, (2019)

16. Sekhar, K., Kushwaha, S.K.S., Karthik, D.R., Mallikarjuna Reddy, V., Mallikarjuna Reddy, B.Transient stability analysis of large scale grid integration of offshore wind and marine current farm connected to grid using STATCOM. Innovations in Power and Advanced Computing Technologies, i-PACT Vellore, 2017, pp. 1-6, doi: 10.1109/IPACT.2017.8244893. 